\title{
Impact of Source Reduction on the Spatial Distribution of Larvae and Pupae of Aedes albopictus (Diptera: Culicidae) in Suburban Neighborhoods of a Piedmont Community in North Carolina
}

\author{
STEPHANIE L. RICHARDS ${ }^{1,2}$, SUJIT K. GHOSH $^{3}$, BRIAN C. ZEICHNER ${ }^{4}$, and CHARLES S. \\ APPERSON 1,5 \\ 1 Department of Entomology, Campus Box 7647, North Carolina State University, Raleigh, NC 27695-7647 \\ 3 Department of Statistics, Campus Box 8203, North Carolina State University, Raleigh, NC 27695-8203 \\ 4 U.S. Army Center for Health Promotion and Preventative Medicine, Aberdeen Proving Ground, Aberdeen, \\ MD 21010
}

\begin{abstract}
Aedes albopictus (Skuse) is a principal nuisance mosquito species and a potential arbovirus vector throughout its geographic range in the United States. This species lays eggs, and progeny complete development in water-filled containers that are discarded in suburban landscapes. Source reduction of containers, achieved through environmental sanitation, was used to experimentally manipulate mosquito production to gain insight into the spatial structure of the population of immature $A e$. albopictus. Our studies were conducted in suburban landscapes in Raleigh, NC, during the 2002 and 2003 mosquito seasons. Spatial analyses, using estimates of the mean and total standing crop of pupae and counts of the numbers of mosquito-positive containers, showed that the distribution of mosquito production was not spatially dependent on a neighborhood-wide basis. However, in all neighborhoods, mosquito production was clustered in at least one and often more than one adjacent residence. Point pattern analyses that considered only the presence or absence of pupae showed that pupae-positive residences were dispersed throughout neighborhoods receiving monthly source reduction treatments and clustered throughout control neighborhoods, indicating that source reduction affected the spatial distribution of pupae. Conversely, spatial analyses based on the presence or absence of larvae and pupae showed that mosquito production was randomly distributed among residences in both control and source reduction neighborhoods, showing that $A e$. albopictus recolonized containers within several weeks after source reduction was implemented. Knowledge of the spatial distribution of production sites would allow management efforts for $A e$. albopictus to be targeted to residences supporting high levels of mosquito production.
\end{abstract}

\section{Keywords}

Aedes albopictus; spatial analysis; geographic information systems; mosquito production; source reduction

Aedes albopictus (Skuse), the Asian tiger mosquito, is an exotic species that was discovered in the United States in the mid-1980s (Hawley et al. 1987). Ae. albopictus is a synanthropic

\footnotetext{
5Corresponding author, e-mail: charles_apperson@ncsu.edu.

2 Present address: University of Florida, Florida Medical Entomology Laboratory, 200 9th St. SE, Vero Beach, FL 32962.

The views expressed in this article are those of the authors and do not reflect the official policy or position of the Department of the Army, Department of Defense, or the U.S. Government.
} 
species, and its use of artificial containers in suburban landscapes as oviposition sites has facilitated the geographic spread of this mosquito (Moore and Mitchell 1997). In the United States, Ae. albopictus is now distributed extensively along the east coast, throughout the southeast, and into the lower midwest (Moore 1999). Conventional methods for measuring abundance of container-inhabiting mosquitoes have primarily involved house-to-house surveys in which mosquito-positive and mosquito-negative containers are counted to derive indices of abundance (Chan et al. 1971, Moore et al. 1978, Barker-Hudson et al. 1988, Nathan and Knudsen 1991). Although this approach allows containers to be quickly examined for mosquitoes, the method ignores differences in the mosquito production capacity of containers, because it assigns equal weight to containers, regardless of the density of immatures.

Consequently, there is no correlation between entomologic indices based on presence of immatures and abundance of adult female mosquitoes (Focks and Chadee 1997). Because the survivorships of pupae and emerging adults are equivalent, a more robust approach involves estimating the mosquito production potential of different types of containers based on their density and standing crop of pupae (Focks and Chadee 1997). However, the importance of containers is also a function of their spatial distribution in the landscape. Aggregation of containers enhances their importance by creating "hot spots" of mosquito production that serve as point sources for reinfestation of neighborhoods (Tun-Lin et al. 1995, Chadee 2004).

The biology of Ae. albopictus is linked to water-filled containers that are distributed throughout suburban landscapes. Monitoring of the spatial distribution and abundance of immature container-inhabiting mosquitoes would help abatement programs to pinpoint "hot spot" areas and would provide a basis for evaluating the effectiveness of control procedures. Spatial statistical methods combined with geographic information systems (GIS)/geographic positioning systems provide a robust set of tools for landscape ecological studies of mosquitoes (Kitron 1998). Here, we describe the spatial distribution of Ae. albopictus immatures across residential landscapes and how environmental sanitation of water-filled containers affected the spatial pattern of mosquito production. Our hypothesis was that production of Ae. albopictus pupae would be clustered at a few residences within neighborhoods and that source reduction would decrease spatial aggregation of containers producing Ae. albopictus larvae and pupae. Accordingly, we conducted backyard surveys so that we could estimate standing crop production of mosquitoes in containers and used distance-based global and local geostatistical and point pattern analysis methods to examine the spatial distribution of mosquito immatures in neighborhoods receiving source reduction treatments.

\section{Materials and Methods}

\section{Study Areas}

Our study was carried out in Raleigh $\left(76.6^{\circ} \mathrm{W}, 35.8^{\circ} \mathrm{N}\right)$, Wake County, NC. Wake County is $2,212 \mathrm{~km}^{2}$ in size and is located in a transitional zone in central North Carolina between the Piedmont and the Coastal Plain. Raleigh presently has $\approx 300,000$ residents. The four suburban neighborhoods used in our study were comprised mainly of single-family dwellings of similar age and size. These neighborhoods were separated by $4-15 \mathrm{~km}$. Study areas were segregated from surrounding neighborhoods by large roadways, woodlands, or complexes of buildings to minimize mosquito immigration. There were from 19 to 28 houses in each neighborhood, with an average of $\approx 50 \mathrm{~m}$ between dwellings and mean lot size of $0.17-0.25$ ha. Landscapes in neighborhoods N-3, N-4, and N-7 consisted of a mixture of deciduous (maple, oak, and elm) and evergreen (pine, cedar) trees intermingled with an understory of unidentified shrubby vegetation. In neighborhood $\mathrm{N}-5$, residential landscapes consisted of open grassy areas and pine woodlands. Ornamental shrubbery was common around homes in all areas, as well as low ground cover such as English ivy. 


\section{Study Design}

Source reduction (SR) achieved through environmental sanitation of containers was used as a method for experimentally manipulating production of Ae. albopictus immatures in container habitats. An incomplete block experimental design (Neter et al. 1996) was used. Experiments were blocked by neighborhood, with one of the two treatments assigned to each neighborhood. Residence and container were sampling units. All residences within neighborhoods were surveyed each month for water-holding containers. Monthly container surveys were initiated in May-June and terminated in October in two neighborhoods in 2002 and in four neighborhoods in 2003. In the 2003 season, the impacts of environmental management on the spatial distribution of Ae. albopictus immatures were evaluated in two SR neighborhoods (N-5 and N-7) in comparison to two control (No-TRT) neighborhoods (N-3 and N-4).

\section{Container Surveys and Source Reduction Treatment}

Within each mosquito season (2002 and 2003), the same survey crew conducted a house-tohouse search in all neighborhoods. Monthly container surveys were completed by a field crew of four to five people that searched the home grounds of each residence for water-holding containers, which were examined for mosquitoes. The areas surrounding each residence were systematically searched for containers out to the property boundary. The type and number of wet mosquito-negative and -positive containers found at each residence were recorded. The contents of each wet container was poured into shallow white enameled pans, and all pupae and a sample of up to 10 larvae were transferred to a Whirl-Pak sample bag (Fisher, Pittsburgh, PA) and labeled with the collection date, house identification code, and container type. If the liquid in the container was turbid or dark, tap water was added to the pans so mosquitoes could be seen. This process was repeated until all of the contents were examined. If the volume of water in the container required what was considered an excessive sampling time, the container was sampled for a standard time of $5 \mathrm{~min}$. Each container, initially identified in the field according to its specific function, was subsequently assigned to a specific category of a classification scheme (plant pot receptacle, bucket, tire, bird bath, tarp, toy, cup/bottle, garbage container, tray/pan, equipment, appliance, miscellaneous). Approximately $8-10 \mathrm{~h}$ were required to complete a container survey in each neighborhood, depending on the numbers of homes and containers present. In general, all neighborhood surveys were completed in the same week.

In No-TRT neighborhoods, once the container was sampled, the contents, without pupae and some larvae, were returned; however, in SR neighborhoods, any remaining contents were discarded, and the container was turned over so that it would not collect rainwater. A wet container that could not be emptied was treated with a granular formulation of the insect growth regulator methoprene (1.5\% Pre Strike; Wellmark, Schumburg, IL).

\section{Processing Mosquito Samples}

After mosquitoes were collected, sample bags were placed on wet ice and transported to the laboratory where mosquitoes were killed in hot water and transferred to labeled vials filled with ethanol. Later, the larvae and pupae in each sample were identified to species using standard keys (Stojanavich 1962, Slaff and Apperson 1989). Ae. albopictus pupae were differentiated from pupae of other species by the presence of a fringe of hairs on the edge of the anal paddle (Harrison 2005). Once identified, pupae were counted, and the counts, along with the container type, were added to the attribute table of a GIS for each residence in the four neighborhoods as described below. 
GIS

Shapefiles for property boundaries, buildings, and street centerlines for all study sites were downloaded from the Wake County government GIS web-site (http://www.wakegov.com/gis/default.htm). All shapefiles and other "data layers" were imported into ArcMap (ESRI 2002), using Universal Transverse Mercator coordinates and the North American Datum 1983 coordinate system. A centroid was placed in the geographic center of the land parcel of each residence to represent the average location for all containers on the property, because containers were not georeferenced during surveys. For container analyses, if there was more than one household on a parcel of land, the same geographic position for the centroid was used for both houses. A shapefile containing these centroids was created with the Feature Analyst extension (ver. 3.4; Visual Learning Systems, Missoula, MT) of ArcMap. Once shapefiles had been created and imported into the GIS, a unique alphanumeric code for each residence was added to the attribute table containing the corresponding centroid. The coordinates of the centroids were used for spatial analyses described later.

\section{Mosquito Production Variables}

The residence and container were base units of study, and metrics of mosquito production (Table 1) were calculated for SR and No-TRT neighborhoods over each mosquito season (2002 and 2003) separately. Planned comparisons were made between SR and No-TRT

neighborhoods to evaluate how altering mosquito production changed the spatial distribution of Ae. albopictus immatures.

\section{Relationship Between Container Abundance and Standing Crop of Pupae}

We determined whether the linear relationship between mean total standing crop of pupae per residence and mean numbers of pupae-positive containers per residence varied between SR and No-TRT areas by Pearson product moment correlation analyses (PROC CORR; SAS Institute 2000) of these two variables within SR and No-TRT areas. In addition, we determined whether the mean total standing crop of pupae per residence and mean numbers of pupaepositive containers per residence were concordant by ranking these two variables by container type within SR and No-TRT areas and computing a separate Kendall's tau-b correlation statistic (PROC CORR), which is a nonparametric measure of association.

\section{Key Container Analysis}

The significance of each type of container to neighborhood mosquito production is a function of its density in the neighborhood landscape and its mean standing crop of pupae (Focks and Chadee 1997). Consequently, we calculated an index of container importance (ICI) for each container type within No-TRT and SR areas by multiplying the mean standing crop of pupae per container per residence by container density (mean number of pupae-positive containers per residence per hectare). Because of the large number of container types, there was a high probability that the mosquito production potential of some container types would be significantly different by chance alone. Therefore, we did not evaluate the statistical significance of differences in mean ICI values between container types.

\section{Key Residence Analysis}

A spatially dependent distribution of containers in the neighborhoods in our study would result in "hot spots" of mosquito production. Consequently, we identified key residences (Focks and Chadee 1997) where Ae. albopictus production occurred. Households that had at least three Ae. albopictus pupae-positive containers in two or more monthly surveys were identified as container key residences (CKRs). After examining our results, we also classified households that had at least three Ae. albopictus pupae-positive containers in three or more survey periods as CKRs. We supplemented the CKR analysis with a pupae key residence (PKR) index, using 
the mean total standing crop of pupae per residence for each neighborhood as the cut-off value for classifying a residence as a PKR. In the 2002 mosquito season, residences in No-TRT where $>43$ total pupae were collected during the entire season were considered PKRs. In the 2003 season, residences with $>71$ and 50 total pupae collected in SR and No-TRT areas, respectively, were classified as PKRs. We also completed separate PKR analyses for households with a mean total standing crop of $>100$ and 200 pupae per residence. These retrospective analyses allowed us to estimate the percentage of the total mosquito production in No-TRT and SR neighborhoods that could have been eliminated by complete source reduction only at these key residences.

\section{Exploratory Analysis of Spatial Data}

Box plots were constructed so that mosquito production variables for each neighborhood could be examined for normality. The general lack of normality was verified with KolmogorovSmirnov tests (PROC UNIVARIATE; SAS Institute 2000). To achieve approximate normality, transformations $[\log (x+1)]$ of mosquito production variables (Table 1 ) were carried out before spatial analyses. These analyses were carried out separately for each neighborhood and mosquito season. Quantitative mosquito production variables were associated with the centroid coordinates of the land parcel of each residence before spatial analyses for residential ("hot spots" of a few residences) and neighborhood clustering analyses were carried out. Categorical (presence or absence) mosquito production variables were also associated with the centroid coordinates of the land parcel of each residence before $K$-function analyses were performed as described below.

\section{Spatial Analyses}

Spatial distribution of mosquito production variables (Table 1) were examined by eye in a GIS for patterns of clustering. Some patterns of clustering were noted for all mosquito production variables so geostatistical methods were used to determine whether clustering patterns were significant and to identify spatial patterns that could not be detected through visual analyses. Our hypothesis was that production of Ae. albopictus at a given residence was more comparable to levels of mosquito production at adjacent versus distant residences within a neighborhood. Geostatistical analyses were performed for mosquito production variables associated with the geo-referenced centroid of each residential land parcel. We created semivariograms to examine the degree of spatial autocorrelation of mosquito production variables between residences within the study neighborhoods using the Geo- $R$ package in $R$ (Ribeiro and Diggle 2001, $\mathrm{R}$ Development Core Team 2004).

Global (neighborhood) spatial characteristics of the same variables were analyzed with the $G$-stat package in $R$ (Pebesma 2004). Local (residence) spatial characteristics of mosquito production variables (Table 1) for each sampling period were analyzed using point pattern analysis (Getis et al. 1998). The spatial distributions of mosquito production variables in SR and No-TRT neighborhoods were examined with the $G_{i}{ }^{*}$ statistic, which measured clustering of similar values around a residence at a specified distance from that residence relative to the entire neighborhood (Ord and Getis 1995). Our hypothesis was that the incidence and intensity of either Ae. albopictus standing crop of pupae or numbers of mosquito-positive containers at the household level would be clustered over multiple, adjacent residences. Analyses of local clustering to identify "hot spot" residences were carried out to a maximum distance of $125 \mathrm{~m}$, because in all neighborhoods, there were no residences where centroids of neighboring properties were $>125 \mathrm{~m}$ apart. Distances between neighbors of residences with significant clustering patterns were measured on a residence-by-residence basis using the measuring tool in ArcMap to determine to what degree the residence was surrounded by a cluster of high or low values of mosquito abundance. The individuality of a residence exhibiting clustering as determined by distance between centroids of residential land parcels varied between 
neighborhoods. For example, if a residence exhibited significant clustering up to $50 \mathrm{~m}$ and neighboring residences were $>50 \mathrm{~m}$ away, it was considered the member of a stand-alone "hot spot."

The traditional measure of global autocorrelation, Moran's I (Schabenberger and Gotway 2005), was modified (Isaacs and Srivastava 1989) to test the degree of clustering of mosquito production variables for each neighborhood.

The $K$-function statistic, $L(d)$, was used to test the null hypothesis that larvae- or pupae-positive houses were not distributed in a spatially random fashion. Effects of key containers (highly mosquito productive types of containers that were difficult to source reduce) on clustering patterns were examined by performing individual spatial analyses, including all containers, only key containers, and containers remaining after exclusion of some key containers.

Accordingly, a $K$-function analysis was completed, using point pattern analysis software (Getis et al. 1998) for residences where mosquitoes were collected. The $K$-function analysis compared the observed locations of pairs of points with their expected locations, assuming complete spatial randomness of points (Gatrell et al. 1996). A detailed description of the $K$-function analysis is presented in Getis et al. (1998). Briefly, observed and expected $L(d)$ values, plotted against distance $(d)$ between centroids of land parcels of residences, were plotted along with a $95 \%$ confidence band for each neighborhood based on the null hypothesis of complete spatial randomness. The $L(d)$ is a linear expression of the expected number of cases occurring within a certain distance $(d)$ of all cases. For our study, $L(d)$ estimated the variance of the distribution of distances between mosquito-positive households. When the line $L(d)=d$ fell inside the $95 \%$ confidence band, the hypothesis of spatial randomness was not rejected; however, if the observed $L(d)$ fell outside of the confidence envelope at any distance, the hypothesis of spatial randomness was rejected. If the observed $L(d)$ fell below the confidence limit at a distance d, the points were dispersed at that distance. If the observed $L(d)$ fell above the confidence limit at a distance $\mathrm{d}$, the points were clustered at that distance.

\section{Results}

\section{Container Abundance}

Four surveys (June-September) were completed in the 2002 mosquito season, and six surveys (May-October) were carried out during the 2003 mosquito season. In surveys of 56 houses in No-TRT neighborhoods in the 2002 and 2003 mosquito seasons, 306 (97\%) of 315 and 511 (44\%) of 1,161 wet containers that were sampled, respectively, contained either larvae or pupae of Ae. albopictus. In two SR neighborhoods, from 44 houses that were sampled in the 2003 mosquito season, $624(49 \%)$ of 1,263 wet containers were positive for immature Ae. albopictus.

\section{Relationship Between Mosquito Production Variables}

We found a significant linear relationship between mean total standing crop of pupae per residence and mean number of pupae-positive containers per residence in No-TRT and SR areas. These two mosquito production variables were significantly correlated in No-TRT $(r=$ $0.852, P<0.0001)$ neighborhoods in 2002 and in No-TRT $(r=0.815, P<0.0001)$ and SR $(r$ $=0.920, P<0.0001$ ) neighborhoods in 2003 .

\section{Mosquito Production Potential of Containers}

We compared the mosquito production potential of the 12 types of containers that were sampled between No-TRT and SR areas by ranking each type of container by its abundance in each area separately. Next, in each area, we ranked the container types according to their mean total standing crops of pupae per residence. When we compared the areas separately, we found no 
significant association between the two ranks in the No-TRT $\left(\tau_{\mathrm{b}}=-0.168, P=0.449\right)$ area in the 2002 mosquito season. There also was no significant association between these ranks for these two variables during the 2003 mosquito season in No-TRT $\left(\tau_{\mathrm{b}}=-0.123, P=0.582\right)$ and $\mathrm{SR}\left(\tau_{\mathrm{b}}=0.075, P=0.753\right)$ areas.

\section{Key Container Analyses}

In the 2002 mosquito season in No-TRT areas, highest mean numbers of pupae were produced in tray/pans (Table 2). However, in the 2003 mosquito season in No-TRT areas, toys produced the highest mean total standing crop of pupae. In contrast, in SR areas, production of pupae was highest in bird baths (Table 2). The mosquito production potential of each type of container is a function of the number of pupae that it contains and its density. Accordingly, we calculated an ICI by multiplying the mean number of pupae-positive containers per residence per hectare by the mean standing crop of pupae per residence for each container type (Tables 2 and 3 ). In No-TRT areas in 2002 and 2003, the mean standing crop of pupae from plant pot receptacles was ranked low; however, when evaluated in conjunction with its density, plant pot receptacles had the highest mosquito production potential. In SR neighborhoods, container types exhibiting highest mosquito production potential included plant pot receptacles, tarps, and garbage containers (Table 3).

\section{Key Residence Analyses}

The spatial aggregation of key containers among residences would potentially influence the spatial distribution of mosquitoes in neighborhoods. Accordingly, we identified key residences for mosquito production based on the types and abundance of containers found during backyard surveys (Table 4). Control efforts focused on PKRs where mosquito production exceeded the neighborhood mean total standing crop of Ae. albopictus pupae per residence would potentially eliminate $75-80 \%$ of the adults produced in No-TRT and SR areas (13 PKRs). In general, orienting control efforts to CKRs with at least three pupae-positive containers in two or more surveys per season would eliminate $34-55 \%$ of mosquitoes in No-TRT neighborhoods and $69 \%$ of mosquitoes in SR areas. If the number of surveys is increased to three or more, control focused on CKRs with at least three pupae-positive containers in three or more surveys would only potentially eliminate $22-26 \%$ of mosquitoes in No-TRT neighborhoods and $51 \%$ of adults in SR neighborhoods. When three or more surveys were conducted, mosquito production exceeding the season long mean standing crop for the area was observed to occur at 2- 8 residences compared with 5-10 residences when two or more surveys were completed (Table $4)$.

\section{Impact of SR on Spatial Distribution of Immature Ae. albopictus}

Neighborhood-specific empirical semivariograms were computed to examine the spatial distribution of mosquito production variables (Table 1) in all four neighborhoods for the 2002 and 2003 mosquito seasons. Our intent was to describe how the spatial distribution of $A e$. albopictus was influenced by SR and not how mosquito abundance was affected by SR.

Neighborhood Clustering of Ae. albopictus Immatures-An exponential model was fitted to the empirical semivariograms using a weighted least square method. When we evaluated distances in 25-m increments out to the entire length of each neighborhood, using a modified Moran's I analysis, we found no significant neighborhood clustering of mosquito production $(P>0.05)$. This finding indicated that mosquito production in each neighborhood was not clustered when all residences were considered simultaneously.

Residential Clustering of Ae. albopictus Immatures-Aggregation of mosquito production at the neighborhood level was not detected, but local clustering of mosquito 
production was found in at least one and often several adjacent residences in all neighborhoods as evidenced by significant $G_{i}{ }^{*}$ values $(P<0.05)$. Figures 1 and 2 show neighborhoods where local spatial clustering was greatest, but clustering or "hot spots" of mosquito production was found in all neighborhoods. Values of $G_{i}^{*} \geq 1.96$ were considered to be an indication that residences were clustered around high levels of mosquito production, whereas values of $G_{i}{ }^{*}$ $<1.96$ were considered to indicate a lack of clustering at the $5 \%$ level of statistical significance. Both SR and No-TRT neighborhoods had seasonally repeating "hot spot" residences for some mosquito production variables. In fact, neighborhoods N-3 and N-5 had at least one household that was a "hot spot" for mosquito production in all six surveys during the 2003 mosquito season. Mosquito production variables were not always concordant in reflecting residences where immatures were clustered. In general, residences where mosquito production was clustered were identified more frequently using mosquito production variables based on occurrence of larvae and pupae rather than abundance of pupae. Across all four mosquito production variables, the number of residences identified as stand-alone "hot spots" varied from zero to seven residences in No-TRT neighborhoods and from one to four in SR neighborhoods. In No-TRT neighborhoods N-3 and N-4, some of the same residences were key residences for clustering of mosquito production in both mosquito seasons (Figs. 1 and 2). In general, however, different "hot spot" residences were identified in each mosquito season. "Hot spots" comprised of more than one residence varied in number from two to four households in No-TRT neighborhoods and only two households in SR neighborhoods. In SR neighborhoods, environmental sanitation of containers producing Ae. albopictus immatures seemed to affect the frequency of occurrence of residences that supported production of $A e$. albopictus immatures compared with No-TRT neighborhoods. The number of residences where immatures were aggregated varied from 3 to 11 households in No-TRT neighborhoods and from 1 to 6 households in SR neighborhoods.

Spatial Distribution of Mosquito-Positive Residences-In the 2002 and 2003 mosquito seasons, $K$-function analyses of the distribution of pupae-positive and pupae- or larvae-positive households were performed for each neighborhood. Pupae-positive houses in No-TRT neighborhoods were generally spatially clustered at a distance of $250-300 \mathrm{~m}$ (Fig. 3A-D). In contrast, households producing pupae in SR neighborhoods were either randomly distributed or spatially dispersed (Fig. 3E and F). When households supporting larvae-positive as well as pupae-positive containers were subjected to spatial analyses, these households were found to be randomly distributed throughout both No-TRT and SR neighborhoods (Fig. 4).

Initially, all peridomestic containers that were positive for pupae were included in $K$-function analyses. Subsequently, when we excluded productive containers that were difficult to eliminate (birdbaths and tarps) from analyses, the spatial clustering of mosquito-positive residences was eliminated, and residences with pupae in No-TRT neighborhoods were randomly distributed (Fig. 5). Separate spatial analyses were carried out on key containers for mosquito production. Plant pot receptacles were distributed randomly in both No-TRT and SR neighborhoods. In contrast, tarps were spatially dispersed or randomly located in No-TRT neighborhoods and randomly located in SR neighborhoods. However, birdbaths were dispersed in No-TRT areas and randomly located in SR areas. $K$-function analyses performed separately on all other types of containers indicated that most containers were located randomly or dispersed within neighborhoods; however, buckets in N-4 were clustered during the 2003 mosquito season.

\section{Discussion}

Production levels of immature Ae. albopictus were correlated with the abundance of mosquitopositive containers. However, there was no association between the ranked abundance of containers and the standing crop of pupae in the containers, indicating that mosquito production 
potential varied between the types of containers that we sampled. Similarly, production of $A e$. aegypti immatures has been reported to differ substantially among the types of containers in most peridomestic environments, with a few specific container types accounting for a large portion of the standing crop of larvae or pupae (see Focks and Alexander 2006 for a review). Survival of pupae is equivalent to emerging adults (Ho et al. 1972), and because the majority of mosquito production is associated with a small number of containers, the density of Ae. aegypti pupae in containers can be used to direct source reduction efforts in environmental sanitation campaigns (Focks and Chadee 1997, Focks et al. 1999). Although Ae. albopictus has been reported to lay eggs in a wide variety of artificial containers (Hawley 1988, Schreiber et al. 1992, Moore 1999, Delatte et al. 2008), our study is the first to estimate the productivity of Ae. albopictus in container habitats in suburban landscapes. The mean standing crop of pupae per container varied widely between No-TRT and SR neighborhoods for specific types of containers, but a significant portion ( 49\%) of the mean total standing crop of pupae per residence across all study neighborhoods was produced by birdbaths, toys, tarps, and garbage containers. In characterizing production of Ae. albopictus in suburban landscapes, we used the concept that the mosquito production potential of each type of container is a function of its local abundance and mean standing crop of pupae (Focks and Chadee 1997, Focks et al. 1999). Our ICI varied between neighborhoods for specific types of containers. In neighborhoods receiving SR, containers that were difficult to eliminate, such as plant pot receptacles, tarps, and garbage containers, were most important as sources of mosquito production. Based on ICI values calculated using container densities and estimates of the standing crop of pupae, the mosquito production potential of the types of containers in our study neighborhoods varied by up to $\sim 60$-fold.

In the 2003 season, in SR neighborhoods, there was no significant association between mean standing crop of pupae per container per residence and mean numbers of pupae-positive containers per residence. These findings may have resulted because containers (e.g., toys) supporting high levels of mosquito production were reduced, causing a shift in oviposition to containers that could not be easily eliminated or source reduced. The large numbers of mosquito samples acquired from tarps and plant pot receptacles in SR areas support this speculation.

We studied the spatial dispersion underlying the distribution of Ae. albopictus immatures in residential neighborhoods by manipulating mosquito production through environmental sanitation of the mosquito's container habitats. We found that the underlying spatial structure of Ae. albopictus pupal production was significantly different than would be expected under the hypothesis of complete spatial randomness. Results of neighborhood-wide container surveys, analyzed within a GIS using spatial statistics, indicated that clustering of $A e$. albopictus pupae generally occurred at the residence level (one or a small group of residences) within key container types. When key containers that were difficult to eliminate were reduced through source reduction and excluded from spatial analyses to simulate source reduction, the aggregated spatial distribution of mosquito-positive residences within neighborhoods became random. Previous spatial analytical research on the distribution of larvae and pupae of container-inhabiting mosquitoes has focused mainly on urban populations of Ae. aegypti (Getis et al. 2003, Morrison et al. 2004). In Iquitos, Peru, Getis et al. (2003) found that houses with Ae. aegypti pupae were dispersed within a neighborhood and that pupae were clustered within houses. Similarly, we found that, in all neighborhoods, households producing Ae. albopictus pupae were clustered.

Production of Ae. albopictus immatures, like Ae. aegypti (Getis et al. 2003), occurs in containers clustered around residences that serve as local "hot spots" of mosquito production. Occurrence of these "hot spots" may vary spatially over time, but some residences are recurrent "hot spots" of mosquito production. Direction of control efforts within neighborhood to "key residences" for Ae. aegypti production has been suggested (Tun-Lin et al. 1995, Chadee 
2004) as a method for improving the efficiency of management programs. The finding that clustering of container-inhabiting mosquitoes can be disrupted is an important consideration for mosquito control agencies seeking to reduce Ae. albopictus abundance. The incidence of clustering among neighboring residences and absence of neighborhood clustering of $A e$. albopictus indicates that focusing control efforts on key residences where mosquito production occurs would be an effective control strategy for this mosquito species.

Nevertheless, container habitats were rapidly repopulated, indicating that source reduction carried out at monthly intervals achieved temporary suppression of Ae. albopictus immatures. It is likely that containers, refilled by rainfall or by residential use of water, were recolonized by mosquitoes emerging from habitats (tarps, bird baths, and plant pot receptacles) that were difficult to eliminate and continued to exist as local "hot spots" of mosquito production.

However, it was clear that source reduction did have an impact on the spatial structure of the population of immature Ae. albopictus. $K$-function analyses indicated that there was a decrease in clustering of residences with pupae. Also, households with containers positive for larvae or pupae were randomly distributed in SR neighborhoods, reflecting the ability of $A e$.

albopictus to quickly recolonize neighborhoods after environmental sanitation. The dispersal of gravid Ae. albopictus, like Ae. aegypti (Edman et al. 1998, Reiter et al. 1995), is driven by the availability of oviposition sites.

Although our study was conducted over a small spatial scale, monthly mosquito surveys increased the power of our analyses. Biotic and abiotic factors affecting the spatial distribution of mosquito production would be of interest to mosquito abatement programs. In a study conducted concurrently in the same neighborhoods, Richards et al. (2006) used ovitraps at fixed stations to characterize oviposition activity of Ae. albopictus populations. A weak spatial dependence of oviposition intensity on the mean standing crop of females was found, but elevated oviposition intensity was not significantly associated with high mean standing crop of pupae in containers or, in general, with the proportion of specific types of land cover surrounding oviposition traps. Richards et al. concluded that gravid females randomly search the landscape for water-filled containers in which to lay eggs. Consequently, in the suburban landscapes included in our study, ovitraps for routine monitoring of Ae. albopictus oviposition activity could not be used to locate key residences for production of immature mosquitoes.

Container habitats of mosquitoes are ecosystem mesocosms that maintain food webs based on organic detritus (Kitching 2000). Microbes, principally bacteria, mineralize carbon from detritus (Moore et al. 2004). Bacteria are principal food items of mosquito larvae (Merritt et al. 1992), and the container habitats of Ae. albopictus support bacterial communities composed of diverse species (Ponnusamy et al. 2008). Catabolism of detritus by bacteria and other microbes produces metabolites that attract and stimulate mosquitoes to oviposit (Clements 1999). Semiochemicals produced through bacterial catalysis of organic matter are used by gravid females as cues to the resource quality in container habitats because bacterial enrichment usually increases the number of females visiting a container and the number of eggs laid by each female (Benzon and Apperson 1988). Consequently, microorganisms potentially exert significant effects on the population dynamics and spatial distribution of mosquitoes in the landscape. Delatte et al. (2008) determined that container habitats that held clear water with a high organic content and placed in moderate shade were optimal habitats for Ae. albopictus larvae and pupae. These findings correlate well with our observations of the containers inhabited by Ae. albopictus in suburban landscapes at our study sites (S.L.R. and C.S.A., unpublished data).

Results of our study indicate that additional research should be carried out to evaluate how eliminating key containers or directing management efforts to key residences affects the movement patterns and dispersal distances of gravid Ae. albopictus as recently suggested by 
Morrison et al. (2004) for Ae. aegypti. This research should be conducted over several spatial scales so that effects of immigration of Ae. albopictus on the level of control can be concurrently evaluated.

\section{Acknowledgements}

We thank G. Powell and H. Tran for field assistance. We are grateful to two anonymous reviewers who made insightful comments that improved the manuscript. Our research was supported in part by funds provided by the Walter Reed Army Institute of Research, the U.S. Army Center for Health Promotion and Preventive Medicine, the North Carolina Pesticide Environmental Trust Fund, and the NIH, NIAID through cooperative agreement U01-(AI)-58303-01.

\section{References Cited}

Barker-Hudson P, Jones R, Kay BH. Categorization of domestic breeding habitats of Aedes aegypti (Diptera: Culicidae) in Northern Queensland. Australia J Med Entomol 1988;25:178-182.

Benzon GL, Apperson CS. Reexamination of chemically mediated oviposition behavior in Aedes aegypti (L.) (Diptera: Culicidae). J Med Entomol 1988;25:158-164. [PubMed: 3392710]

Chadee DD. Key premises, a guide to Aedes aegypti (Diptera: Culicidae) surveillance and control. Bull Entomol Res 2004;94:201-207. [PubMed: 15191621]

Chan YC, Chan KL, Ho BC. Aedes aegypti (L.) and Aedes albopictus (Skuse) in Singapore City. 1 Distribution and density. Bull WHO 1971;44:617-627. [PubMed: 5316745]

Clements, AN. The biology of mosquitoes, vol. 2: sensory reception and behaviour. CABI publishing; Oxford, United Kingdom: 1999.

Delatte H, Dehecq JS, Thiria J, Domerg C, Paupy C, Fontenille D. Geographic distribution and developmental sites of Aedes albopictus (Diptera: Culicidae) during a Chikungunya epidemic event. Vector-Borne Zoon Dis 2008;8:25-34.

Edman JD, Scott TW, Costero A, Morrison AC, Harrington LC, Clark GG. Aedes aegypti (Diptera: Culicidae) movement influenced by availability of oviposition sites. J Med Entomol 1998;35:578583. [PubMed: 9701948]

ESRI. ArcGIS geostatistical analyst: powerful exploration and data interpolation solutions. 2001. http:www.esri.com

Focks DA, Chadee DD. Pupal survey: an epidemiologically significant surveillance method for Aedes aegypti: an example using data from Trinidad. Am J Trop Med Hyg 1997;56:159-167. [PubMed: 9080874]

Focks, DA.; Alexander, N. TDR (Special Programme for Research and Training in Tropical Diseases). Geneva, Switzerland: 2006. Multicountry study of Aedes aegypti pupal productivity survey methodology.

Focks DA, Brenner RJ, Chadee DD, Trosper J. The use of spatial analysis in the control and risk assessment of vector-borne diseases. Am Entomol 1999;45:173-183.

Gatrell A, Bailey T, Diggle P, Rowlingson B. Spatial point pattern analysis and its application in geographic epidemiology. Trans Inst Br Geogr 1996;21:256-274.

Getis, A.; Hungerford, L.; Chen, D.; Aldstadt, J. Point pattern analysis version 1.0a. 1998. http://www.nku.edu/ longa/cgi-bin/cgi-tcl-examples/generic/ppa/ppa.cgi

Getis A, Morrison AC, Gray K, Scott TW. Characteristics of the spatial pattern of the dengue vector, Aedes aegypti, in Iquitos, Peru. Am J Trop Med Hyg 2003;69:494-505. [PubMed: 14695086]

Harrison BA. Easily seen characters to identify the pupa of Aedes albopictus (Diptera: Culicidae) in the United States. J Am Mosq Control Assoc 2005;21:451-454. [PubMed: 16506571]

Hawley W. The biology of Aedes albopictus. J Am Mosq Control Assoc (suppl) 1988;4:2-32.

Hawley W, Reiter P, Copeland R, Pumpuni C, Craig GB Jr. Aedes albopictus in North America: probable introduction in used tires from northern Asia. Science 1987;29:1114-1116. [PubMed: 3576225]

Ho, BC.; Chan, KL.; Chan, YC. The biology and bionomics of Aedes albopictus (Skuse). In: YowCheong, C.; Kai-Lok, C.; Beng-Chuan, H., editors. Proceedings of the First SEAMO Workshop. Singapore: 1972 Aug 17-18. p. 125-143. 
Isaacs, ER.; Srivastava, R. An introduction to applied geostatistics. Oxford University Press; New York: 1989.

Kitching, RL. Food webs and container habitats: the natural history and ecology of phytotelmata. Cambridge University Press; Cambridge, United Kingdom: 2000.

Kitron UD. Landscape ecology and epidemiology of vector-borne diseases: tools for spatial analysis. J Med Entomol 1998;35:435-445. [PubMed: 9701925]

Merritt RW, Dadd RH, Walker ED. Feeding behavior, natural food, and nutritional relationships of larval mosquitoes. Annu Rev Entomol 1992;37:349-377. [PubMed: 1347208]

Moore CG. Aedes albopictus in the United States: current status and prospects for further spread. J Am Mosq Control Assoc 1999;15:221-227. [PubMed: 10412117]

Moore CG, Mitchell CJ. Aedes albopictus in the United States: ten-year presence and public health implications. Emerg Infect Dis 1997;3:329-334. [PubMed: 9284377]

Moore CG, Cline BL, Ruiz-Tiben E, Lee D, Romney-Joseph H, Rivera-Correa E. Aedes aegypti in Puerto Rico: environmental determinants of larval abundance and relation to dengue virus transmission. Am J Trop Med Hyg 1978;27:1225-1231. [PubMed: 727328]

Moore JC, Berlow EL, Coleman DC, de Ruiter PD, Dong Q, Hastings A, Johnson NC, McCann KS, Melville K, Morin PJ, Nadelhoffer K, Rosemond AD, Post DM, Sabo JL, Scow KM, Vanni MJ, Wall DH. Detritus, trophic dynamics, and biodiversity. Ecol Lett 2004;7:584-600.

Morrison AC, Gray K, Getis A, Astete H, Sihuincha M, Focks D, Watts D, Stancil J, Olson J, Blair P, Scott TW. Temporal and geographic patterns of Aedes aegypti (Diptera: Culididae) production in Iquitos, Peru. J Med Entomol 2004;41:1123-1142. [PubMed: 15605653]

Nathan MB, Knudsen AB. Aedes aegypti infestation characteristics in several Caribbean countries and implications for integrated community-based control. J Am Mosq Control Assoc 1991;7:400-404. [PubMed: 1791448]

Neter, J.; Kutner, M.; Nachtsheim, C.; Wasserman, W. Applied inear statistical models. McGraw-Hill; Boston, MA: 1996.

Ord J, Getis A. Local spatial autocorrelation statistics: distribution issues and application. Geogr Anal 1995;27:286-306.

Pebesma E. Multivariable geostatistics in $S$ : the Gstat package. Comput Geosci 2004;30:683-691.

Ponnusamy L, Xu N, Stav G, Wesson DM, Schal C, Apperson CS. Diversity of bacterial communities in the container habitats of mosquitoes. Micro Ecol. 2008in press

R Development Core Team. A language and environment for statistical computing. 2004. http://www.r-project.org

Reiter P, Amador M, Anderson R, Clark GG. Short report: Dispersal of Aedes aegypti in an urban area after blood-feeding as demonstrated by rubidium-marked eggs. Am J Trop Med Hyg 1995;52:177179. [PubMed: 7872449]

Ribeiro PJ, Diggle PJ. GeoR: A package for geostatistical analysis. R News 2001;1/2:15-18.

Richards SL, Apperson CS, Ghosh SK, Cheshire HM, Zeichner BC. Spatial analysis of Aedes albopictus (Diptera: Culicidae) oviposition in suburban neighborhoods of a Piedmont community in North Carolina. J Med Entomol 2006;43:876-989.

SAS Institute. SAS/STAT user's guide for personal computers, ver. 8.0. SAS Institute; Cary, NC: 2000.

Schabenberger, O.; Gotway, C. Statistical methods for spatial data analysis. Chapman \& Hall/CRC; Boca Raton, FL: 2005.

Shrieber ET, Chamberlain S, Thomas R, Parsons R, Baker G. Surveys on artificial container inhabitingmosquitoes in Sarasota and Tallahassee, Florida, 1: Characteristics of larval habitats. J Florida Mosq Control Assoc 1992;63:7-15.

Slaff, M.; Apperson, CS. A key to the mosquitoes of North Carolina and the Mid-Atlantic states. NC State University; Raleigh, NC: 1989.

Stojanavich CJ. Keys to the common mosquitoes of the eastern U.S. Ohio Biol Survey Note 1962;17:156.

Tun-Lin W, Kay BH, Barnes A. The premise condition index: a tool for streamlining surveys of Aedes aegypti. Am J Trop Med Hyg 1995;53:591-594. [PubMed: 8561259] 


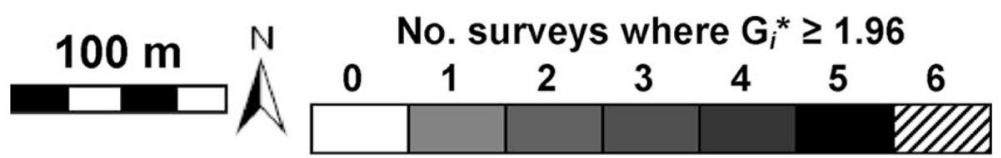

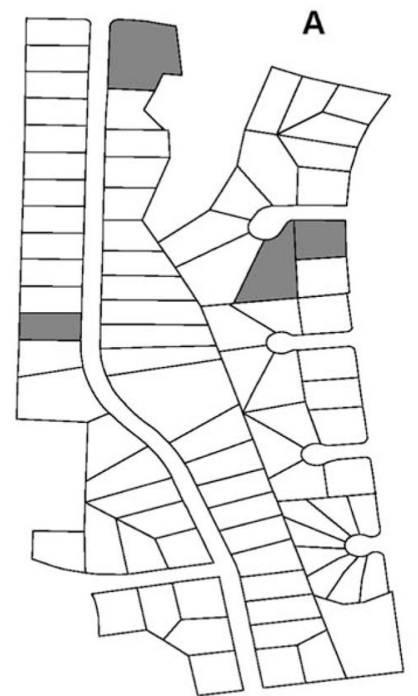

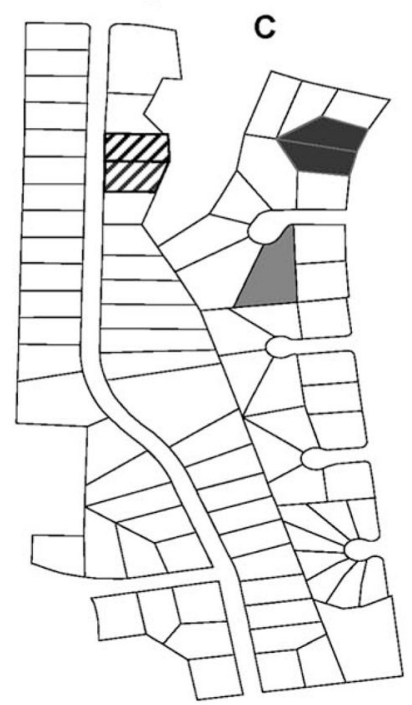

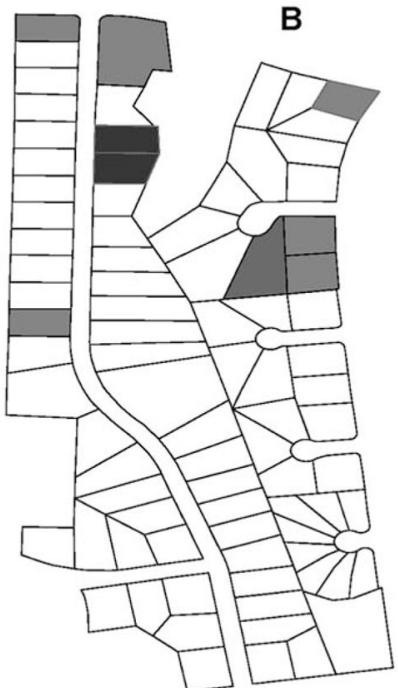

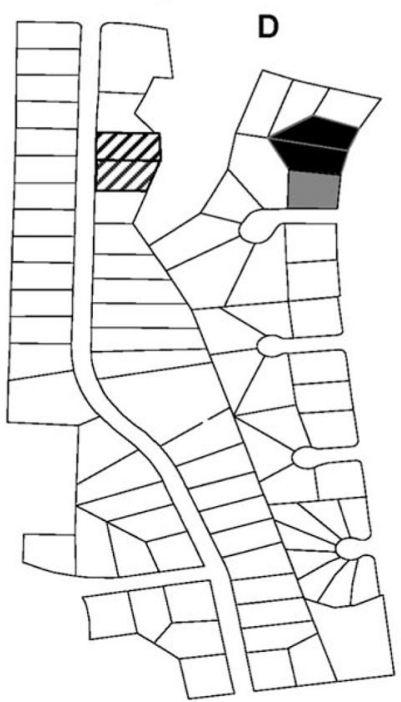

Fig. 1.

$G_{i}^{*}$ maps showing clustering of immature Ae. albopictus in neighborhood N-3 (No-TRT) in 2003. (A) Mean total standing crop of pupae per residence. (B) Mean standing crop of pupae per container per residence. (C) Mean numbers of pupae-positive containers per residence. (D) Mean numbers of pupae- or larvae-positive containers per residence. 

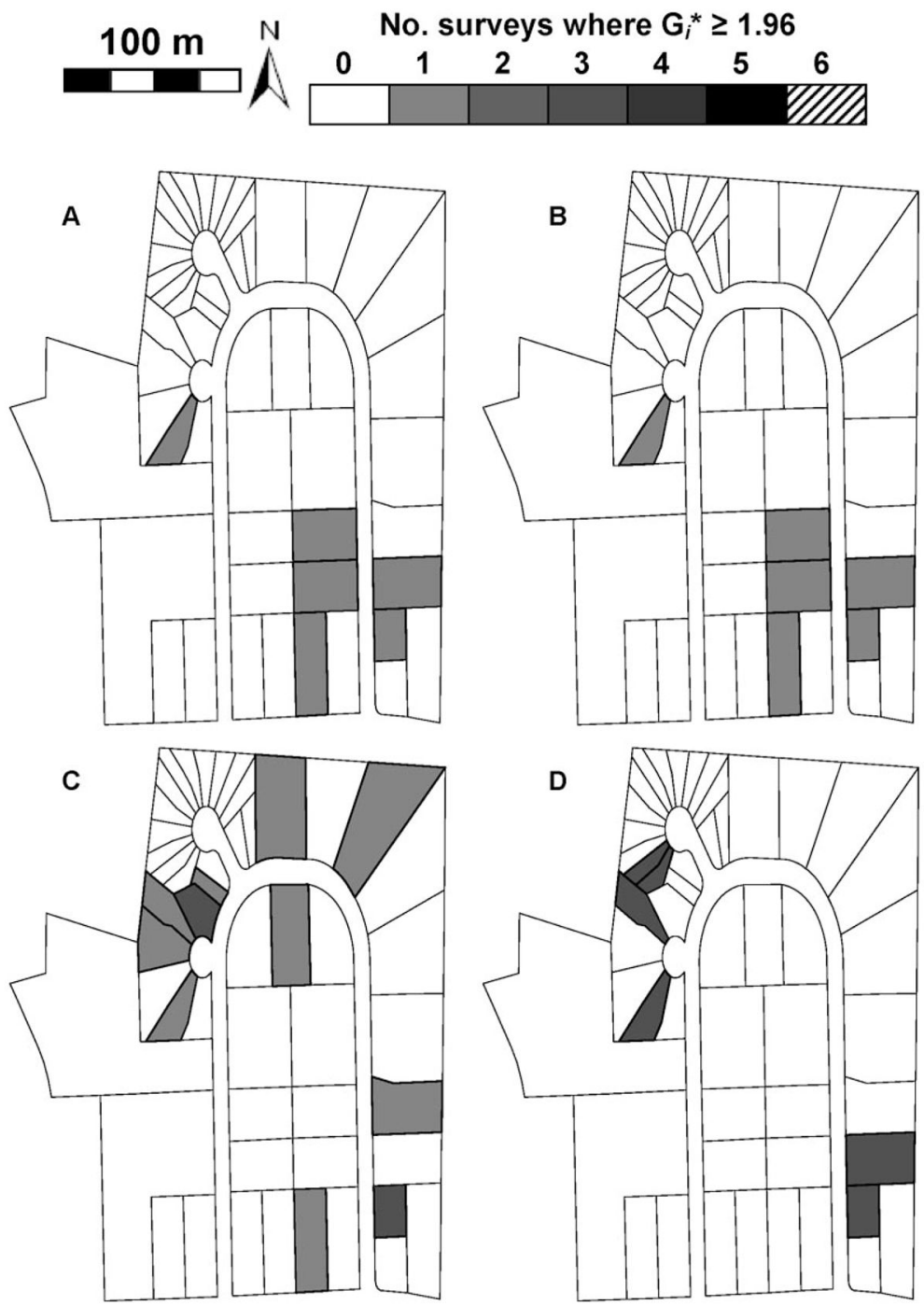

Fig. 2.

$G_{i}{ }^{*}$ maps showing clustering of immature Ae. albopictus in neighborhood N-4 (No-TRT) in 2003. (A) Mean total standing crop of pupae per residence. (B) Mean standing crop of pupae per container per residence. (C) Mean numbers of pupae-positive containers per residence. (D) Mean numbers of pupae- or larvae-positive containers per residence. 


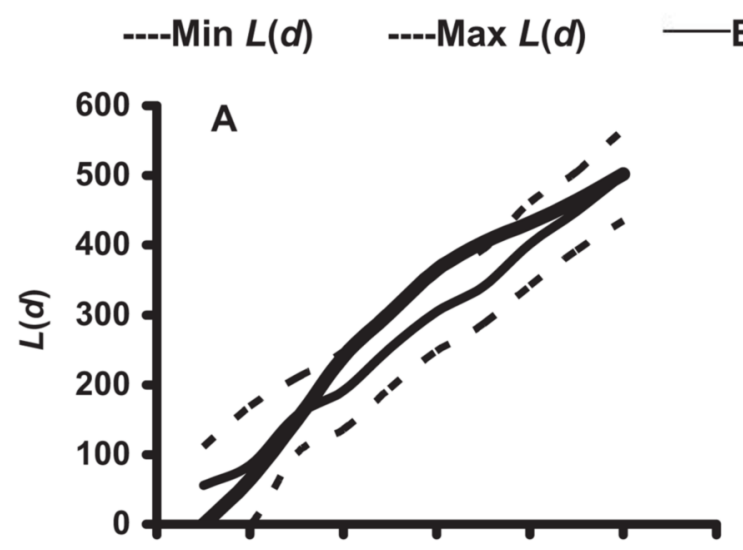

Expected $L(d) \quad$ Observed $L(d)$
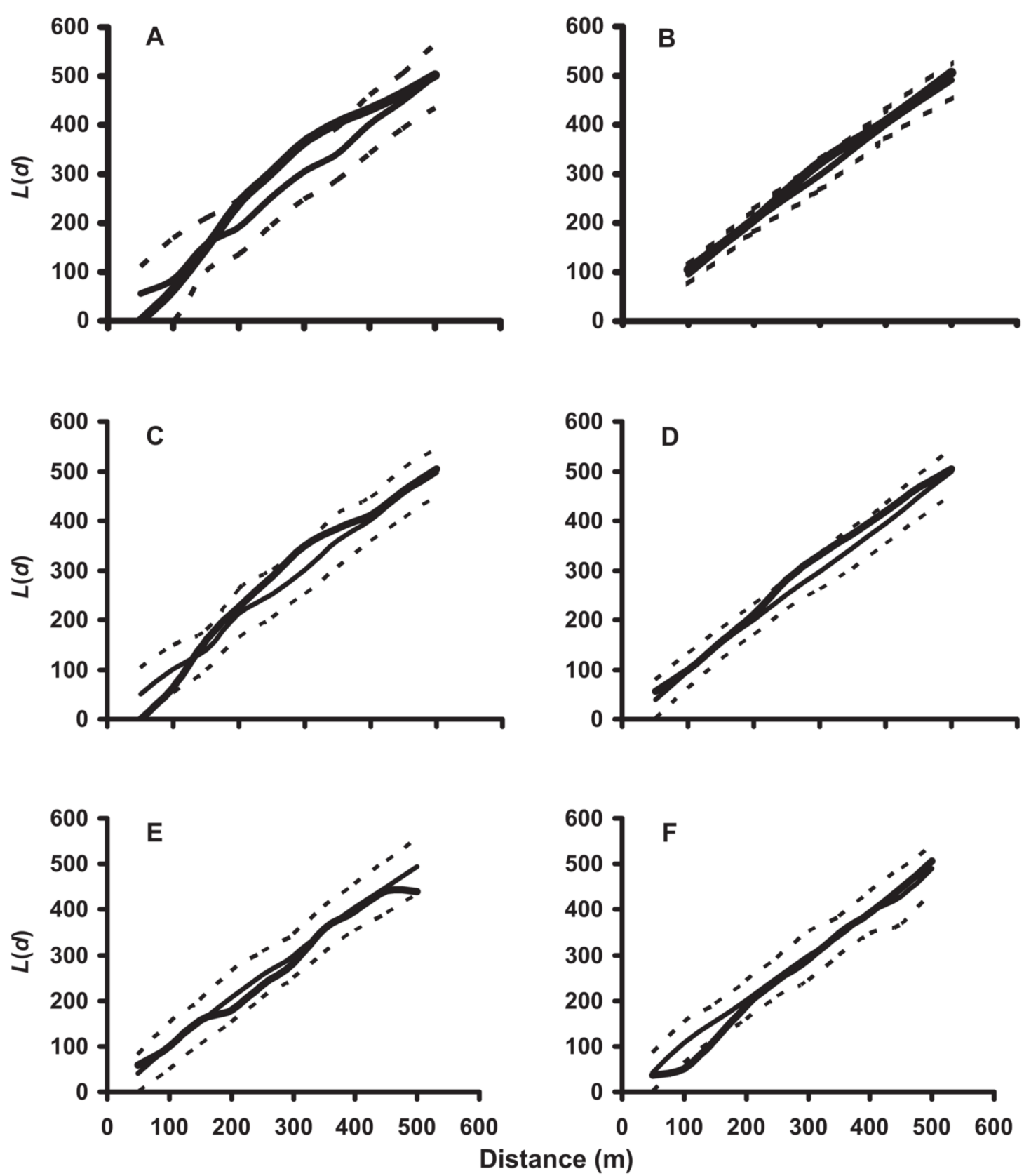

Fig. 3.

Results of $K$-function (second order) analysis of the spatial distribution of Ae. albopictus pupaepositive containers in neighborhoods not receiving source reduction in 2002, N-3 (A) and N-4 (B), and 2003, N-3 (C) and N-4 (D), and neighborhoods receiving source reduction in 2003, N-5 (E) and N-7 (F). 


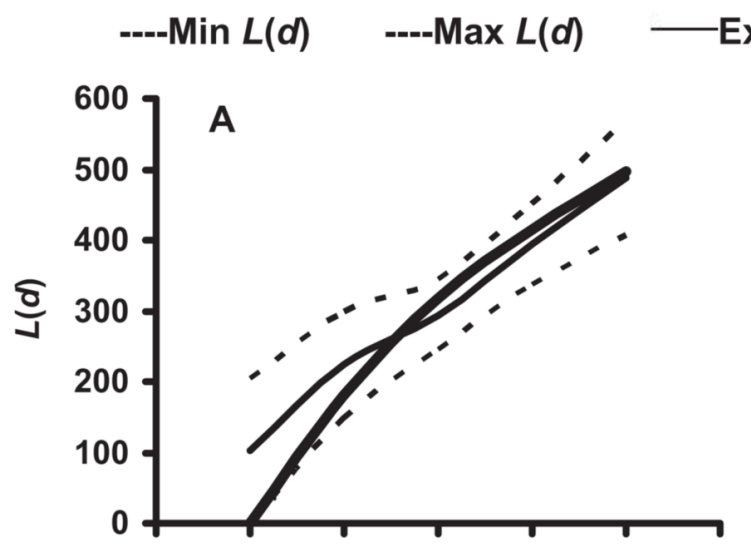

Expected $L(d) \quad$ Observed $L(d)$
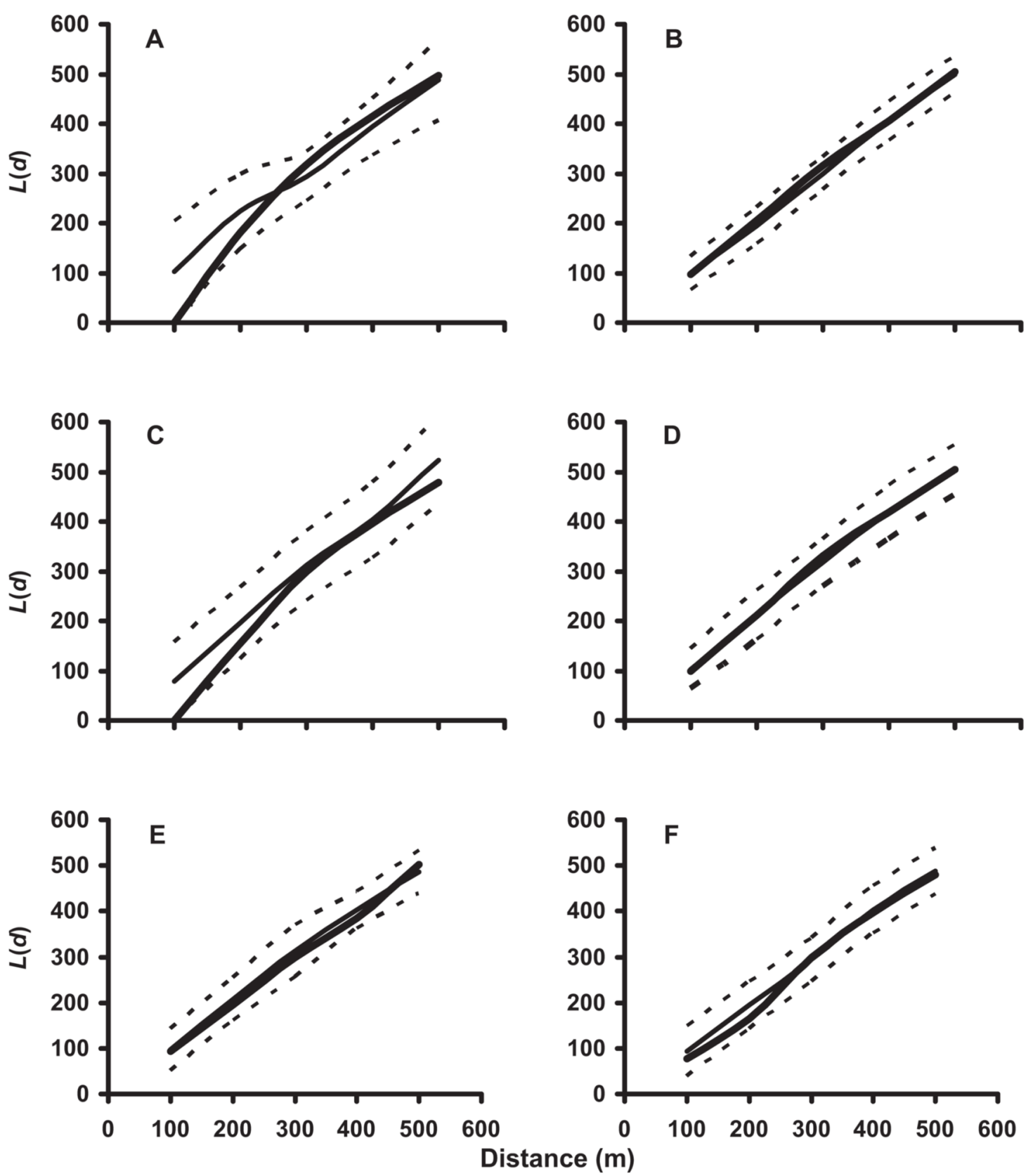

Fig. 4.

Results of $K$-function (second order) analysis of the spatial distribution of Ae. albopictus larvaepositive or pupae-positive containers in neighborhoods not receiving source reduction in 2002, N-3 (A) and N-4 (B), and 2003, N-3 (C) and N-4 (D), and neighborhoods receiving source reduction in 2003, N-5 (E) and N-7 (F). 

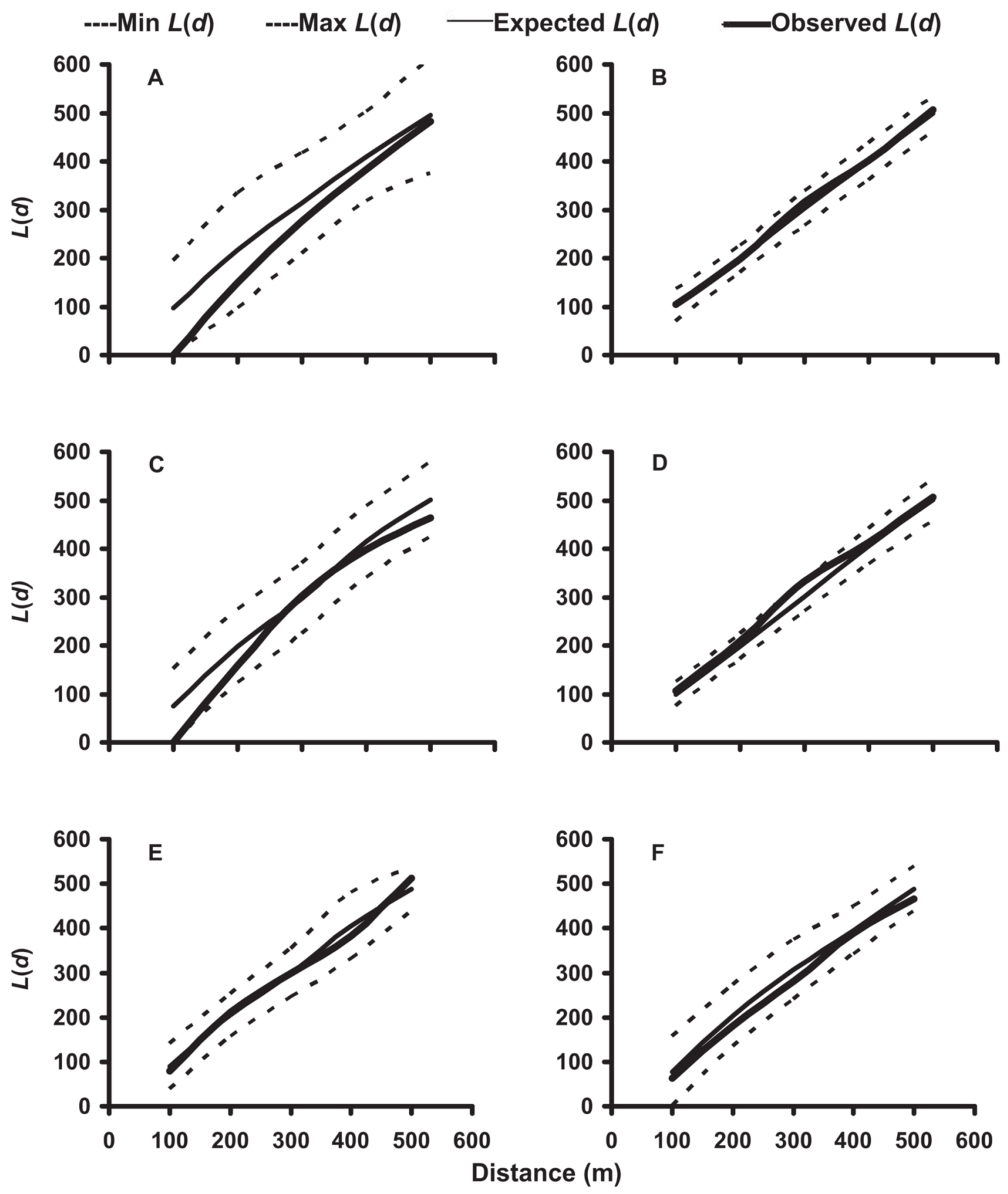

Fig. 5.

Results of $K$-function (second order) analysis of the spatial distribution of Ae. albopictus pupaepositive containers (except tarps and bird baths) in neighborhoods not receiving source reduction in 2002, N-3 (A) and N-4 (B), and 2003, N-3 (C) and N-4 (D), and neighborhoods receiving source reduction in $2003, \mathrm{~N}-5$ (E) and N-7 (F). 
Table 1

Mosquito production variables analyzed at the neighborhood and household level over the period of each container survey and over the entire mosquito season

\begin{tabular}{|c|c|}
\hline Variable & Description \\
\hline Standing crop of pupae in a container & $\begin{array}{l}=\text { no. of pupae }(p) \text { collected in container type } k(k=1, \cdots, 12) \text { in the jth household }\left(j=1, \cdots, j_{i}\right) \text { of } \\
\text { ith neighborhood }(i=\mathrm{N}-3, \mathrm{~N}-4, \mathrm{~N}-5, \mathrm{~N}-7)\end{array}$ \\
\hline Total numbers of pupae-positive containers & $=$ no. of containers $(N)$ of type $k$ in the $j$ th household of the ith neighborhood \\
\hline Total standing crop of pupae per residence & $\begin{array}{l}=\text { sum of the numbers of pupae collected in all containers or in each specific container type per } \\
\text { residence }\end{array}$ \\
\hline $\begin{array}{l}\text { Mean standing crop of pupae per container per } \\
\text { residence }\end{array}$ & $\begin{array}{l}=\text { sum of the numbers of pupae collected in all containers/total numbers of all containers per } \\
\text { residence }\end{array}$ \\
\hline $\begin{array}{l}\text { Mean standing crop of pupae per container type } \\
\text { per residence }\end{array}$ & $\begin{array}{l}=\text { sum of the numbers of pupae collected in each type of container/total numbers of each specific } \\
\text { container per residence }\end{array}$ \\
\hline $\begin{array}{l}\text { Mean numbers of pupae-positive containers per } \\
\text { residence }\end{array}$ & $\begin{array}{l}=\text { sum of the numbers of pupae-positive containers/total numbers of residences per neighborhood } \\
(R)\end{array}$ \\
\hline $\begin{array}{l}\text { Mean numbers of pupae- or larvae-positive } \\
\text { containers per residence }\end{array}$ & $=$ sum of the numbers of pupae- or larvae-positive containers $/ R$ \\
\hline
\end{tabular}


RICHARDS et al.

Page 19

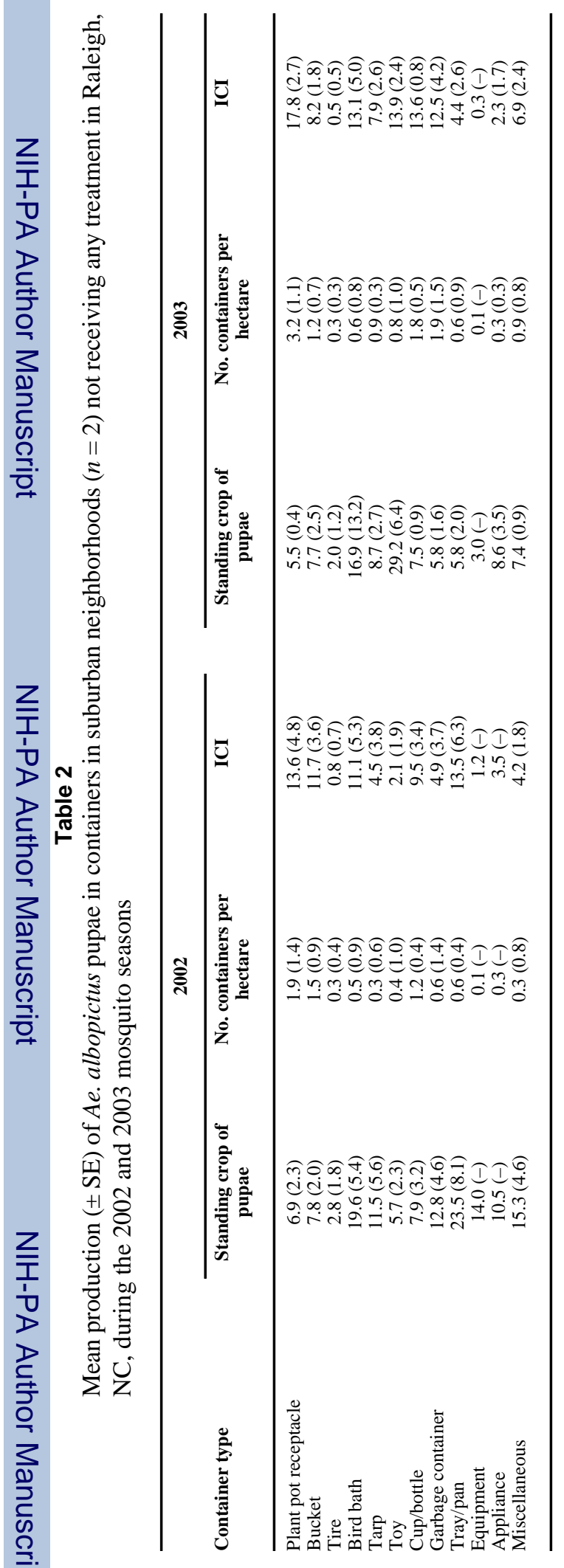

J Med Entomol. Author manuscript; available in PMC 2008 November 25. 
Table 3

Mean production $( \pm \mathrm{SE})$ of Ae. albopictus pupae in containers in suburban neighborhoods receiving source reduction $(n=2)$ treatments in Raleigh, NC, during the 2003 mosquito season

\begin{tabular}{|c|c|c|c|}
\hline Container type & Standing crop of pupae & No. containers per hectare & ICI \\
\hline Plant pot receptacle & $6.0(0.5)$ & $5.7(1.4)$ & $33.6(3.2)$ \\
\hline Bucket & $7.5(1.0)$ & $0.7(1.0)$ & $4.6(2.8)$ \\
\hline Tire & $8.4(2.5)$ & $1.1(1.3)$ & $6.4(2.8)$ \\
\hline Bird bath & $14.3(2.0)$ & $1.4(0.9)$ & $18.7(2.4)$ \\
\hline Tarp & $6.8(2.5)$ & $4.2(2.4)$ & $37.2(8.0)$ \\
\hline Toy & $10.3(-)$ & $0.3(-)$ & $3.4(-)$ \\
\hline Cup/bottle & $5.3(1.7)$ & $1.6(0.7)$ & $9.0(2.7)$ \\
\hline Garbage container & $10.5(0.7)$ & $2.5(1.7)$ & $26.0(5.4)$ \\
\hline Tray/pan & $3.3(-)$ & $0.3(-)$ & $1.1(-)$ \\
\hline Equipment & $9.0(-)$ & $0.3(-)$ & $2.9(-)$ \\
\hline Appliance & $-(-)$ & $-(-)$ & $-(-)$ \\
\hline Miscellaneous & $3.6(1.4)$ & $1.0(1.2)$ & $4.4(2.7)$ \\
\hline
\end{tabular}


RICHARDS et al.

Page 21

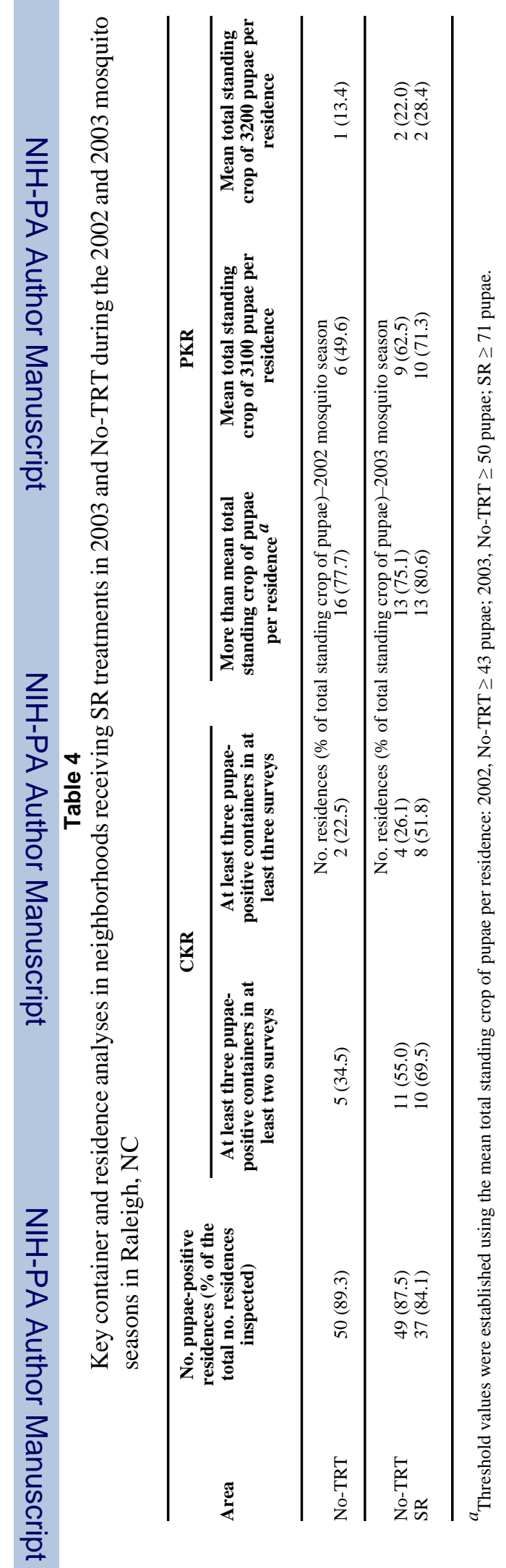

J Med Entomol. Author manuscript; available in PMC 2008 November 25. 